\title{
BMJ Open Have restricted working hours reduced junior doctors' experience of fatigue? A focus group and telephone interview study
}

\author{
Gill Morrow, ${ }^{1}$ Bryan Burford, ${ }^{2}$ Madeline Carter, ${ }^{1}$ Jan Illing ${ }^{1}$
}

To cite: Morrow G, Burford B, Carter M, et al. Have restricted working hours reduced junior doctors' experience of fatigue? A focus group and telephone interview study. BMJ Open 2014:4:e004222.

doi:10.1136/bmjopen-2013004222

- Prepublication history for this paper is available online. To view these files please visit the journal online (http://dx.doi.org/10.1136/ bmjopen-2013-004222).

Received 10 October 2013 Revised 3 February 2014 Accepted 10 February 2014

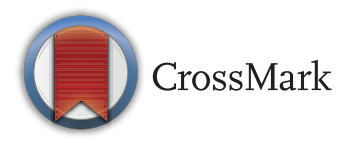

${ }^{1}$ Centre for Medical Education Research, Durham University, Durham, UK

${ }^{2}$ School of Medical Sciences Education Development, The Medical School, Newcastle University, Newcastle upon Tyne, UK

\section{Correspondence to}

Prof Jan Illing;

j.c.illing@durham.ac.uk

\section{ABSTRACT}

Objective: To explore the effects of the UK Working Time Regulations (WTR) on trainee doctors' experience of fatigue.

Design: Qualitative study involving focus groups and telephone interviews, conducted in Spring 2012 with doctors purposively selected from Foundation and specialty training. Final compliance with a $48 \mathrm{~h} /$ week limit had been required for trainee doctors since August 2009. Framework analysis of data.

Setting: 9 deaneries in all four UK nations; secondary care.

Participants: 82 doctors: 53 Foundation trainees and 29 specialty trainees. 36 participants were male and 46 female. Specialty trainees were from a wide range of medical and surgical specialties, and psychiatry.

Results: Implementation of the WTR, while acknowledged as an improvement to the earlier situation of prolonged excessive hours, has not wholly overcome experience of long working hours and fatigue. Fatigue did not only arise from the hours that were scheduled, but also from an unpredictable mixture of shifts, work intensity (which often resulted in educational tasks being taken home) and inadequate rest. Fatigue was also caused by trainees working beyond their scheduled hours, for reasons such as task completion, accessing additional educational opportunities beyond scheduled hours and staffing shortages. There were also organisational, professional and cultural drivers, such as a sense of responsibility to patients and colleagues and the expectations of seniors. Fatigue was perceived to affect efficiency of skills and judgement, mood and learning capacity.

Conclusions: Long-term risks of continued stress and fatigue, for doctors and for the effective delivery of a healthcare service, should not be ignored. Current monitoring processes do not reflect doctors' true working patterns. The effectiveness of the WTR cannot be considered in isolation from the culture and context of the workplace. On-going attention needs to be paid to broader cultural issues, including the relationship between trainees and seniors.

\section{INTRODUCTION}

There is a considerable body of evidence recognising that fatigue has adverse

\section{Strengths and limitations of this study}

- The strength of the study is the breadth of trainee participants, covering a range of training grades and specialties and all four nations of the UK.

- A potential weakness is that participants were volunteers to the study, and as such may be open to self-selection bias. However, this risk is mitigated by the instance of one group run as part of Foundation Programme teaching, where all but four of a cohort of Foundation Year One trainees (F1s) were able to attend. That group identified the same issues as the wider sample, suggesting the prevalence of the issues identified is not limited to a particularly engaged sample.

- There may also be potential inaccuracies in individual recall of hours worked.

physiological, psychological and cognitive effects and can lead to deficits in performance and safety. ${ }^{1}$ Fatigue in doctors is associated with increases in risks to personal safety at work $^{2}{ }^{3}$ and outside work, ${ }^{4}$ and risks to health and well-being. ${ }^{6-9}$ There is also evidence of detriments to performance, for example, in cognitive abilities ${ }^{10}{ }^{11}$ and psychomotor skills ${ }^{12-14}$ (although some studies have found no performance effects ${ }^{15}{ }^{16}$ ). Fatigue has also been associated directly with negative consequences for patient safety, such as clinical errors and diagnostic mistakes. ${ }^{4} 5{ }^{17-20}$ This has been a concern in medicine for several years $^{21}$ and remains so today. ${ }^{22}{ }^{23}$ The effects may be compounded by a risk that doctors do not recognise that they may be subject to adverse effects. ${ }^{23}$

Several countries have introduced limits on working hours. For example, in the USA, since 2003, there has been national implementation of an Accreditation Council for Graduate Medical Education (ACGME) $80 \mathrm{~h}$ resident work week restriction, averaged over 4 weeks; however, the limit is lower in Europe. The 
European Working Time Directive (EWTD) was introduced to limit hours, to address health and safety concerns for all workers arising from long hours. Each European Union member state implemented the Directive in its own legislation-the UK as the Working Time Regulations (1998). These Regulations (the WTR) have applied fully to junior doctors since 2009, with a limit of $48 \mathrm{~h}$ /week, averaged across a reference period of 26 weeks, alongside specified minimum rest periods. The WTR are implemented in rotas (work schedules) alongside the New Deal, which specifies a maximum of $56 \mathrm{~h} /$ week, with a system of banded payments.

Positive effects of a reduction in working hours have been found in many studies, ${ }^{24-26}$ but not all. ${ }^{27} 28$ The effect varies with the precise implementation of restrictions, with fatigue affected by work patterns, including the number of consecutive days or nights worked, the intervals between shifts and the timing of shifts (day/ evening/night). ${ }^{29-31}$ Short naps may ameliorate the negative effects of fatigue, ${ }^{32}$ and awareness of the benefits of naps and other recommendations and interventions to limit fatigue associated with rotating shift work may be needed. ${ }^{33}$

Organisational cultures of long or antisocial hours ${ }^{34}$ may also be a factor impacting on stress and fatigue, and trainees have reported being unofficially expected to work extra hours voluntarily. ${ }^{35}$ Furthermore, workload pressures and poor work design may increase risks of negative behaviours among staff. ${ }^{36}$ Limits on professional autonomy-the amount of control doctors have traditionally held over their practice-may also increase doctors' stress and reduce job satisfaction. ${ }^{37-39}$

Consequently, simply restricting the number of work hours may be insufficient to address issues relating to fatigue and its consequences. With this in mind, the question is raised whether the WTR will have achieved the aim of improving junior doctors' well-being and fatigue. To date, there has been little research looking directly at the effects of the WTR as implemented and experienced in practice. This paper draws on a larger research study considering perceptions of the effects of the $\mathrm{WTR}^{40}$ and focuses specifically on their effects on trainee doctors' fatigue.

\section{METHOD}

The research was reviewed by the Durham University School of Medicine, Pharmacy and Health Ethics Sub-Committee, and a favourable ethical opinion received.

Focus groups and telephone interviews (with participants who were unable to attend a focus group) were conducted with Foundation Year One (FY1) and FY2 trainees and specialty trainees, sampled purposively from nine deaneries in all four nations of the UK. The Foundation Programme is a 2-year generic training programme undertaken after completing medical school and is followed by specialist or general practice training. The WTR apply to all years of training in the same way.
The focus group topic guide and interview questions focused on perceptions and experience of working hours following the WTR and any educational or personal impact. Trainees were asked about their knowledge of the WTR; their perceptions of their working hours in practice, including shifts, rotas and compliance; issues concerning educational opportunities; monitoring of working hours and any personal effects they experienced. Some specialty trainees had experience of working before the introduction of the WTR and were asked about the change.

Recruitment was undertaken following local advice; in some cases through the Deanery, in others through education centres in individual hospitals. An information sheet about the study was distributed to trainees via email from the Deaneries or individual Trusts, and participation was on a voluntary basis. Written consent was taken at the start of focus groups and verbal consent at the start of telephone interviews, including consent for audio recording. Recordings were later transcribed. GM and $\mathrm{BB}$ conducted the focus groups and telephone interviews. Focus groups lasted between 60 and $90 \mathrm{~min}$, and telephone interviews between 30 and $45 \mathrm{~min}$.

\section{ANALYSIS}

Data were analysed using a framework approach. ${ }^{41}$ An initial stage of familiarisation, to gain an overall view of the data, involved reading the transcripts and noting the range and depth in the data collected. Meetings between all four researchers engaged in this process (GM, BB, MC and JI) enabled discussion of the concepts and themes that emerged from the data. A thematic framework was subsequently identified by GM and BB. This involved identifying the key issues, concepts or themes by which the data could be examined and sorted. The construction of the framework drew on:

- A priori issues: those issues that were known or assumed to be pertinent, that guided the study aims and were developed into the topic guide/interview schedule;

- Emergent issues: those issues that were raised by the respondents (eg, issues relating to work intensity);

- Analytic issues: those themes that emerged from patterns and reoccurrences in the data (eg, professionalism).

The framework was then applied to the data by GM and $\mathrm{BB}$ through indexing and charting, and themes and subthemes were further refined. Finally, a stage of mapping and interpretation involved bringing the key themes within the data set together and pulling together the findings of the analysis as a whole. Figure 1 summarises the main a priori, emergent and analytic themes related to fatigue and illustrates the mapping and interpretation of the themes. The process of analysis helped provide an explanation of why fatigue remains an issue, and of the inter-relatedness of the issues identified.

Data from focus groups and telephone interviews were analysed concurrently and no differences in themes were identified. 


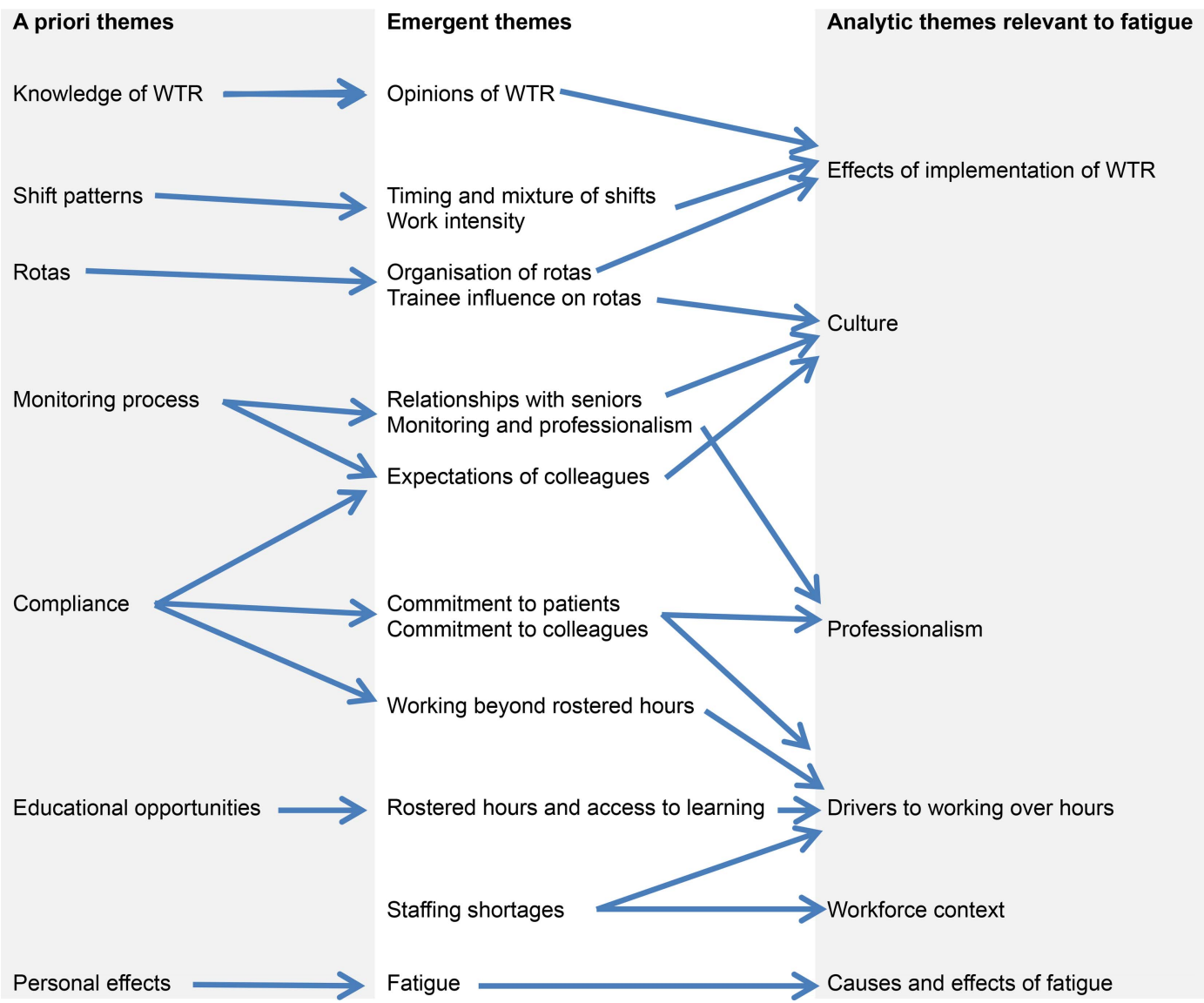

Figure 1 Development of themes in framework analysis.

\section{Findings}

Eleven focus groups and 30 telephone interviews were conducted with 82 junior doctors.

See table 1 for details of the training grades of participants.

Thirty-six participants were male and 46 female. Specialty trainee participants were training in a wide range of medical and surgical specialties, and psychiatry.

An overview of the Findings from the data is presented in table 2 below.

\section{Perceived effects of the WTR on working hours}

There was general agreement that working hours were much improved under the WTR, and that intended benefits in terms of reduced trainee fatigue and improved work-life balance had been achieved to some extent. Many trainees felt that the $48 \mathrm{~h}$ limit was appropriate and enabled sufficient training experience, albeit with a perceived lack of flexibility.

I think, speaking to people who didn't have the forty-eight hour working time directive thing, we get a lot more time to go home and enjoy ourselves and be outside the hospital than they ever did and I think that's a good thing, I feel like I've got a bit more of a life. (Tel. Int. 22, Foundation)

Implementation of the WTR in practice: effects on fatigue However, some participants did report still working long hours and experiencing fatigue despite the $48 \mathrm{~h}$ limit, and this was found to be related to a number of factors, including the way in which the Regulations were implemented and other organisational and contextual factors.

The WTR have not entirely eliminated long hours, with some trainees giving examples of working up to

Table 1 Training grades of participants

\begin{tabular}{llll}
\hline Foundation Year $\mathbf{1}$ (FY1) & Foundation Year $\mathbf{2}$ (FY2) & Core or specialty training up to CT/ST3* & ST4 or highert \\
\hline 40 & 13 & 7 \\
Total Foundation trainees: 53 & Total specialty trainees: 29 \\
\hline${ }^{*}$ These are trainees in the first 3 years of their specialty training, and were likely to have started specialty training after the WTR introduction in \\
2009. \\
†These are in higher specialty training, in their fourth year or above.
\end{tabular}


Table 2 Overview of findings

\begin{tabular}{ll}
\hline Overall findings & Detail of findings \\
\hline $\begin{array}{l}\text { Perceived effects of the WTR on working } \\
\text { hours }\end{array}$ & $\begin{array}{l}\text { General agreement that working hours were much improved under the WTR; } 48 \mathrm{~h} \\
\text { limit appropriate (but desire for greater flexibility); intended benefits achieved to } \\
\text { some extent }\end{array}$ \\
$\begin{array}{ll}\text { Implementation of the WTR in practice: } \\
\text { effects on fatigue }\end{array}$ & $\begin{array}{l}\text { Different shift systems and patterns of work (timing and adjustment) } \\
\text { Long periods without a day off }\end{array}$ \\
& Averaging over 26 weeks can still allow over 48 working hours in one week \\
& Work compression/work intensity \\
& Rest periods not always taken \\
& Workload/completion of tasks \\
Drivers to work long hours & Taking up educational opportunities at work \\
& Taking work home \\
& Commitment and responsibility to patients and colleagues; collegiality \\
& Cultural expectations \\
& Professional reputation \\
& Views of nature of professionalism \\
& Workforce issues \\
& Detriment to skills and judgement: most felt to affect efficiency rather than safety \\
& Negative effect on ability to retain new information \\
Mood and manner (compounded by physical discomfort and hunger)
\end{tabular}

$100 \mathrm{~h}$ in a week. However, fatigue did not necessarily arise just from the long hours worked, but also from the organisation of work within those hours, for example, the mixture of day and night shifts, and long shifts straddling day and night (eg, 14:00 to 2:00). Rotas could involve 5 consecutive days at work with $13 \mathrm{~h}$ shifts, and working up to 12 consecutive days or, for some, 7 consecutive nights (despite Royal College recommendations to the contrary). Trainees reported that averaging meant that a working week could exceed $70 \mathrm{~h}$ and remain compliant.

I don't think the hours are long, so doing a 12 hour day or 13 hour day is fine, I think doing 12 days in a row you hit delirium about day ten and then you over-ride it...so I don't think it's the shift I think it's the number of days you work in a row. (Focus group 3, Foundation)

There's no continuity in terms of predictability of, right this is what I'm doing and, for example, my rota you run an eight cycle rota so you've got eight weeks to get through and none of those eight weeks are the same at all, and you jump around with longs and lates in-between and I think that from my side is what creates fatigue. (Focus group 10, Specialty)

That was a particularly difficult shift on the assessment suite because you would go from five long days with maybe two days off, or a day off sometimes, and then onto a period of nights, you are constantly swapping from nights to days which was tiring, and 12 hour shifts and 13 hour shifts were always a bit of a drag. (Tel. Int. 22, Foundation)

There was also a perception that $12 \mathrm{~h}$ shifts were more fatiguing, with less 'down-time' than longer but less intense on-call sessions. Work intensity was also increased by rotas involving cross-cover out of hours.

My personal opinion is [the WTR have] actually increased fatigue and stress in the fact that you feel you have to get an increased amount of work done in a shorter amount of time. (Tel. Int. 16, Foundation)

Provision of facilities for taking rest during a night shift was also being reduced which, alongside less capacity to take breaks or compensatory rest, added to the fatigue experienced. Rest periods were also lost in half days-sometimes inserted into rotas to balance hoursnot always being taken, sometimes because senior clinical staff were unaware of them, so workload did not respond to working hours.

The trouble with night shift is being able to sleep during the day and most hospitals have no facility to actually catch a nap while on nights. The last time I worked in a hospital with bedrooms for on-call staff was in 2007 and that's despite guidance from the Royal College of Physicians that it should be possible for someone to have a short nap. (Tel. Int. 23, Specialty)

The difficulty is you may be entitled to various half days but the chances of them actually materialising are very slight ... unless these things are really formalised and recognised they just don't happen. I mean you can just about get your half day off before nights because everyone understands that you're about to start nights ... but the rest of them just don't happen. (Tel. Int. 19, Foundation) 


\section{Drivers to work long hours}

Fatigue did not just arise from hours specified in rota design. There were many reasons, including some voluntary, for trainees working beyond their rostered (scheduled) hours.

Some reasons for working longer hours than scheduled stemmed from the capacity to fit workload into the working period. This was more evident in shift work, where there was a feeling that incoming doctors in the evening may not have the capacity to perform nonurgent tasks, so the present doctor would finish those tasks before leaving. In contrast, in on-call rotas, a trainee would simply pass the bleep to the incoming doctor and so have a cleaner handover.

You kind of know yourself if I was to leave this work it's only going to be there for me in the morning and there's a ward round in the morning, so I will have to get loads more work handed my way. So you want to get things finished. (Tel. Int. 2, Foundation)

Other drivers came from missing educational opportunities if trainees did not attend work outside the rota, including going to work on rostered days off. These opportunities included attending ward rounds and observing in theatre. While benefits of the WTR for worklife balance were perceived, there was a sense that some educational activity that had been part of the 'work' domain was now being taken home. This included portfolio completion and reading that may have been done in the workplace during slack periods on-call.

If you haven't got enough time to eat or go to the toilet, you can't leave work on time, then you definitely don't have time to go to clinics, you definitely don't have time to do audits or anything like that during work, it basically means that anything that is exclusively for your own training is basically done in your own time and the amount of time available to you is really diminished. (Tel. Int. 7, Specialty)

Although this increased their working hours and reduced time for rest and recuperation, the benefit of taking up such opportunities was often seen to outweigh this.

I've got no problems with the fact that I work a little bit over and take the extra time to get training opportunities and that increases my hours to get better at my job. That's personal sacrifice, personal advancement type stuff to get a better job to become a consultant. (Focus group 11, Specialty)

There were also professional and cultural reasons for working beyond rostered hours. These related to the expectations and norms perceived among their professional group and the workplace. Trainee doctors often worked beyond rostered hours due to a sense of commitment and responsibility, both to patients and to colleagues. There were cases of trainees staying late to hand over the care of a patient, rather than force two handovers (eg, where a junior doctor would stay to complete an admission in A\&E, rather than hand over to another FY2 doctor, who would then have to hand over to the specialty where the patient was being admitted), owing to concern for continuity of care and the risk of information being lost. There was also a strong sense of collegiality, expressed as a responsibility not to burden colleagues with routine tasks, particularly as they were likely to face other immediate demands at the handover time.

We have just never taken the half days because we're so busy, you know; we could have done, but would have screwed over our colleagues. (Focus group 2, Foundation)

At times, however, this could be perceived as a cultural expectation that some jobs would not be left—so less a choice, more an imposition. There were references to a negative culture where trainees could experience pressure from senior doctors, and other professions, to stay beyond their rostered hours, with an implication of unprofessionalism if they left on time. There was also a perception among trainees that their professional reputation was at risk, with implications for an employment reference and future career.

Concerns about working hours were often not recognised or appreciated by seniors, with some respondents identifying a dismissive attitude towards the WTR, and a feeling that such limitations were counter to medical professionalism. Some trainees also agreed that limited hours undermined professional autonomy, a feeling exacerbated if hours were enforced during the periodic 2-week monitoring process.

If you clicked that you started at 8.00 and you were meant to start at 9.00, you had to explain...why did you do it, so quite a lot of the time I wouldn't put down that I started before 9.00 because I knew I was going to have to justify that I came in before 9.00. (Focus group 5, Foundation)

Trainees reported that, as the WTR compliance is derived from these New Deal monitoring reports, there was no objective record of hours worked, and there were also no formal measures for health and well-being. However, few trainees kept their own record of hours worked despite their being conscious of working beyond rostered hours. This was partly due to their view of medicine and the nature of their work, meaning that working to limited hours was not an issue to them.

We are treated usually like we are working late due to our own failings which is not a nice atmosphere to work in, I think it's very important that you feel you are working, especially as a junior in a new career, you're working somewhere you are appreciated, valued and not being looked at suspiciously. (Tel. Int. 21, Foundation)

Gaps in rotas also placed additional pressure on the system, and so on individual doctors. These arose from staff shortages caused by under-recruitment, as well as 
absences. This often meant providing informal cover, for example in extended shifts. While locums were used, external locums were felt to be sometimes unreliable, meaning last minute cover was often necessary. Formal internal locum shifts were sometimes used and crossreferenced against rotas to ensure an individual did not exceed the WTR hours, and there was no reported pressure to undertake locum shifts. The trainees reported that there was a shortage of available doctors to fill rotas, even without the need to comply with the WTR. Some trainees felt that even fully staffed rotas would be stretched because the workload had increased since the staffing levels were initially put in place.

The fundamental issue is trying to do a decent job and you can't do a decent job if there aren't enough of you on the ground, so you are always working many hours in excess of what you should be doing, you end up tired and exhausted and jaded and then you're not doing a good job for your patient. (Tel. Int. 29, Foundation)

\section{Effects of fatigue}

Trainees identified effects of fatigue arising from their working hours. While detriments to their skills and judgement were identified, these were mostly felt to affect efficiency rather than safety-however, risks to patient safety cannot be discounted. Some reported that fatigue affected their ability to retain new information.

I think when you were getting to the end of a thirteen hour shift you found that your technical skills, like your ability to put a cannula into someone and stuff like that, it certainly decreases, I find it gets a lot harder to do things that require more concentration, things like that, but I think you're also quite aware of that, so patient safety wise you are aware that you are not at your best so you often check more of your decisions with other people and things like that. (Tel. Int. 22, Foundation)

I think 12 days in a stretch is too long without a day off, I just think it's a really long stretch...I think [the effect] is fatigue really and I suppose you learn less towards the end of those days really because you are just tired. (Tel. Int. 26, Foundation)

Fatigue was also reported to affect mood, particularly when switching between different working patterns, with consequences for their professional manner. This may have consequences for teamworking and interprofessional communication, as well as for interactions with patients.

You become more irritable sometimes as well, I noticed I was a bit more snappy [when switching between long days and nights] (Focus group 5, Foundation)

You don't make as good decisions and you're more grumpy, you're less likely to be good with the patients, you know, you're more likely to just go in there and take the blood rather than actually you know being a doctor to them ... so you have to be a lot more careful when you're tired I suppose. (Tel. Int. 9, Foundation)

These issues were sometimes compounded by hunger and discomfort arising from not achieving rest breaks during long shifts.

I think when I'm hungry my fuse is shorter and I think my compassion towards others is not as what it should be. (Tel. Int. 2, Foundation)

\section{DISCUSSION}

Despite the introduction of restricted working hours for junior doctors in the UK, long hours and fatigue remain, with associated consequences for performance. There was general agreement that restricting working hours was a positive thing, but problems remained with acute workload in some working patterns. Conversely, while most felt that a $48 \mathrm{~h}$ limit was appropriate, some would like more flexibility to exceed it when necessary.

It was considered that the amount of work to be carried out had not reduced, increasing the perceived intensity of work. Some working patterns were considered particularly intense and detrimental to personal well-being-with consequences for performance and education. Long periods without a day off in particular were tiring. There is no objective record of hours worked, as the WTR compliance is derived from New Deal monitoring reports, and trainees reported no formal measures for health and well-being.

There was evidence that the design of rotas was not the only factor working against well-being. Trainees were often working beyond their rostered hours for voluntary reasons of workload, perceived need to gain educational opportunities and collegiality, but also for more external reasons such as the expectations of others and gaps in the rota. Notably these are corollaries of the voluntary reasons-rota gaps increase workload, and adverse cultures may define professional practice. Contrary to recent recommendations to 'make every moment count' towards education in the workplace, ${ }^{42}$ for some trainees at least there is increasing separation between work and education and an increase in work intensity that may be adding new stresses to the trainee population.

The current study provides evidence that 3 years after the implementation of the WTR, and with rotas that are at least compliant on paper, fatigue remains an issue for doctors in training. This reflects some findings in the literature that a reduction in working hours alone is not enough. The issue of increased work intensity and greater stress was noted among US residents when working hours were further restricted. ${ }^{43}$ Performing the same amount of work in fewer hours (work compression) is of concern regarding workload ${ }^{44}$ and overall well-being, ${ }^{45}$ and may place trainee doctors at risk of burnout. ${ }^{46}$ Although much of the literature relating to fatigue comes from the USA where restricted working hours are still much longer than in Europe (eg, 
$80 \mathrm{~h} /$ week and longer maximum shift lengths), two UK self-report studies conducted shortly after implementation of the $48 \mathrm{~h}$ working week have highlighted the effect of different schedules on fatigue, including the negative effect of working 7 consecutive nights, having only 1 day of rest after night shifts, intervals of less than $10 \mathrm{~h}$ between shifts, and shifts of 12 consecutive days. ${ }^{30} 31$ Difficulty achieving naps during night shifts, and poor provision for naps, has been reported elsewhere. ${ }^{33}$ The current study has identified that fatigue is related to a number of complex issues, including rota design, but also including contextual issues such as staff shortages and rota gaps, and broader professional and cultural issues.

Cultural issues within healthcare have been found to include fatigue not being taken seriously, lack of discussion of fatigue issues and lack of support for napping. ${ }^{47}$ The culture of medicine needs to value sleep and appropriate work schedules. ${ }^{48}$ Long working hours may be a symptom of, and contribute to, an adverse culture. Expectations of long hours, coupled with a lack of their explicit recognition, may be symptomatic of 'institutionalised disrespect' of workers, ${ }^{34}$ which, if it is felt to be normal, may lead to further dysfunctional behaviours. Culture, particularly at the level of basic underlying assumptions, that may underpin day-to-day work, can be extremely difficult to change. ${ }^{3449}$ In a study of paramedics, podiatrists and occupational therapists, the working environment was found to be an important factor in encouraging and developing professionalism. ${ }^{50}$ Some trainees in the current study felt undermined by aspects of the professional and organisational culture and felt there was a lack of recognition of the extra hours they worked. This was compounded by pressure from seniors to work and record compliant hours during monitoring periods, even if that was unrepresentative of the usual functioning of the rota. This highlights tensions that can be experienced by trainee doctors who are required to work in compliance with the WTR but also meet the demands of the healthcare service and the needs of patients, and simultaneously want to satisfy their own professional standards and maximise their educational opportunities.

In other professions and industries the organisation of work, and the professional and organisational cultures they engender or reinforce (such as a culture of long working hours and cultural attitudes towards napping), has also been linked to fatigue, performance, safety, health and well-being. Such professions and industries include nursing,${ }^{51}$ aviation,${ }^{52}$ the police,${ }^{53}$ truck driving, ${ }^{54}$ the shipping industry ${ }^{55}$ and the construction industry. ${ }^{56}$ It has also been found, in a study of metropolitan train drivers, that the successful adoption of fatigue management strategies can be positively or negatively affected by aspects of the organisational culture, such as altruism and camaraderie. ${ }^{57}$ A culture of denial of vulnerability to stress and the effects of fatigue on performance has been identified in both aviation and medicine, ${ }^{58}$ although one study found this to a lesser extent in aviation. ${ }^{59}$
Work hours are closely related to psychosocial work characteristics such as work demands and autonomy. ${ }^{60}$ Optimal amount and quality of workload, and opportunities for control at work are among the psychosocial criteria identified for a good work environment and good work organisation, and typically show dependence on national and organisational culture and values; ${ }^{61}$ however, individual differences in the desire or need for control need to be taken into account. ${ }^{62}$ High work demands and work intensity, and lack of autonomy (and particularly a combination of these) have been associated with health problems. ${ }^{63}$ In a study of US nurses, high job demands were associated with greater fatigue when job control was low. ${ }^{64}$ The ability to influence working hours (worktime control) has been associated with fewer subjective health complaints, ${ }^{65}$ and with decreased work strain and decreased perceived stress. ${ }^{66}$

The broader cultural issues identified in relation to trainees' professional autonomy and the relationship between trainees and their seniors are of current relevance in light of the Francis report's recommendations for fundamental culture change in the National Health Service (NHS) ${ }^{67}$ Following these recommendations, it has been argued that more sophisticated understandings of cultural dynamics and the role of policy in shaping these may be needed. ${ }^{68}$ Fatigue may be an important mediating variable in the perpetuation of adverse cultures and practice failings, and as such should be an important component of any policies to monitor and improve workplace cultures.

Evaluation of the WTR must be considered in relation to the historical context within which they were implemented. Perceptions of the WTR were not isolated from other changes affecting working hours, particularly the 1991 New Deal for Junior Doctors, which imposed restrictions for the first time. At an organisational level, changes relating to the reorganisation of specialty training over the past 20 years $^{69}$ affected the working environment. Trainees now have to settle on a career specialty training path sooner, meaning that the Senior House Officer (SHO) posts they would have filled in other specialties for several years may remain unfilled. These gaps are compounded by the reduction in the number of overseas-qualified doctors entering the UK following changes to immigration policy in 2008. The workload and hence fatigue experienced by individual trainees can therefore be seen as the end-point of many contributory factors.

\section{Strengths and limitations}

The strength of the current study is the breadth of trainee participants, covering a range of training grades and specialties and all four nations of the UK, so gaining a picture across the trainee experience. A weakness is that the trainee participants were volunteers to the study, and as such may be open to self-selection bias. However, this risk is mitigated by the instance of one group, run as part of Foundation Programme teaching, where all but four of a cohort of F1s were able to attend. 
That group identified the same issues as the wider sample, suggesting the prevalence of the concerns identified is not limited to a particularly engaged sample. There may also be some instances of inaccuracy in individual recall regarding the exact hours trainees worked.

\section{Conclusion}

The WTR have reduced the hours junior doctors work, but have not fully addressed problems of fatigue and stress, owing to issues in their implementation and other contextual factors. The long-term risks of this continued stress and fatigue, for the doctors themselves and for the effective delivery of a healthcare service, should not be ignored.

Future research could usefully involve an investigation of work intensity and its effects on doctors' education, performance and well-being, and its impact on patient care. Such research should consider the clinical demands of different specialties and the working environment. Policy and practice could consider how best to monitor both working hours and doctors' well-being. The closer and more effective involvement of trainees in rota design, with consideration of the physiological aspects of sleep and fatigue, may help to avoid some stresses, but there may need to be more fundamental consideration of necessary staffing levels.

Acknowledgements The authors thank all the trainee doctors who took part in focus groups or telephone interviews.

Contributors This article draws on research commissioned by the UK General Medical Council, designed by GM and BB, and conducted by all authors. All authors contributed to the analysis and writing of the report and the writing of this article, and approved the final version. All four authors were members of the Centre for Medical Education Research, Durham University, UK, when this research was carried out. GM and $\mathrm{JI}$ are guarantors.

Funding This research was funded by the General Medical Council. Competing interests None.

Ethics approval Durham University School of Medicine, Pharmacy and Health Ethics Sub-Committee.

Provenance and peer review Not commissioned; externally peer reviewed.

Data sharing statement No additional data are available.

Open Access This is an Open Access article distributed in accordance with the Creative Commons Attribution Non Commercial (CC BY-NC 3.0) license, which permits others to distribute, remix, adapt, build upon this work noncommercially, and license their derivative works on different terms, provided the original work is properly cited and the use is non-commercial. See: http:// creativecommons.org/licenses/by-nc/3.0/

\section{REFERENCES}

1. Morrow G, Burford B, Carter M, et al. The impact of the working time regulations on medical education and training: literature review. Report to the GMC, August 2012. http://www.gmc-uk.org/The_ Impact_of_the_Working_Time_Regulations_on_Medical_Education_ and_Training_LLiterature_Review.pdf_51155615.pdf

2. Ayas NT, Barger LK, Cade BE, et al. Extended work duration and the risk of self-reported percutaneous injuries in interns. JAMA 2006;296:1055-62.

3. Fisman DN, Harris AD, Rubin M, et al. Fatigue increases the risk of injury from sharp devices in medical trainees: results from a case-crossover study. Infect Control Hosp Epidemiol 2007;28:10-17.
4. Barger LK, Ayas NT, Cade BE, et al. Impact of extended-duration shifts on medical errors, adverse events, and attentional failures. PLoS Med 2006;3:e487.

5. Gander P, Purnell H, Garden A, et al. Work patterns and fatigue-related risk among junior doctors. Occup Environ Med 2007;64:733-8.

6. Kohen-Raz R, Himmelfarb M, Tzur S, et al. An initial evaluation of work fatigue and circadian changes as assessed by multiplate posturography. Percept Mot Skills 1996;82:547-57.

7. Parshuram CS, Dhanani S, Kirsh JA, et al. Fellowship training, workload, fatigue and physical stress: a prospective observational study. CMAJ 2004;170:965-70.

8. Smith AM, Morris P, Rowell KO, et al. Junior doctors and the full shift rota-psychological and hormonal changes: a comparative cross-sectional study. Clin Med 2006;6:174-7.

9. Block L, Wu AW, Feldman L, et al. Residency schedule, burnout and patient care among first-year residents. Postgrad Med $\mathrm{J}$ 2013;89:495-500

10. Gohar A, Adams A, Gertner E, et al. Working memory capacity is decreased in sleep-deprived internal medicine residents. J Clin Sleep Med 2009;5:191-7.

11. Lockley SW, Cronin JW, Evans EE, et al. Effect of reducing interns weekly work hours on sleep and attentional failures. N Engl J Med 2004;351:1829-37.

12. Jakubowicz DM, Price EM, Glassman HJ, et al. Effects of a twenty-four hour call period on resident performance during simulated endoscopic sinus surgery in an Accreditation Council for Graduate Medical Education-compliant training program. Laryngoscope 2005;115:143-6.

13. Gander P, Millar M, Webster C, et al. Sleep loss and performance of anaesthesia trainees and specialists. Chronobiol Int 2008;25:1077-91.

14. Brandenberger J, Kahol K, Feinstein AJ, et al. Effects of duty hours and time of day on surgery resident proficiency. Am J Surg 2010;200:814-18.

15. Ellman PI, Law MG, Tache-Leon C, et al. Sleep deprivation does not affect operative results in cardiac surgery. Ann Thorac Surg 2004;78:906-11.

16. Lehmann KS, Martus P, Little-Elk S, et al. Impact of sleep deprivation on medium-term psychomotor and cognitive performance of surgeons: prospective cross-over study with a virtual surgery simulator and psychometric tests. Surgery 2010;147:246-54.

17. Grantcharov TP, Bardram L, Funch-Jensen P, et al. Laparoscopic performance after one night on call in a surgical department: prospective study. BMJ 2001:323:1222-3.

18. Landrigan CP, Rothschild JM, Cronin JW, et al. Effects of reducing interns' work hours on serious medical errors in intensive care units. N Engl J Med 2004;351:1838-48.

19. Lockley SW, Landrigan CP, Barger LK, et al. Harvard Work Hours, Health Safety Group. When policy meets physiology: the challenge of reducing resident work hours. Clin Orthop Relat Res 2006;449:16-127.

20. Majekodunmi A, Landrigan CP. The effect of physician sleep deprivation on patient safety in perinatal-neonatal medicine. $\mathrm{Am} \mathrm{J}$ Perinatol 2012;29:43-8.

21. Vorona RD, Chen IA, Ware JC. Physicians and sleep deprivation. Sleep Med Clin 2009;4:527-40.

22. Paice E, Hamilton-Fairley D. Avoiding burnout in new doctors: sleep, supervision and teams. Postgrad Med J 2013;89:493.

23. Sokol DK. Waking up to the effects of fatigue in doctors. $B M J$ 2013;347:\{4906

24. Conigliaro J, Frishman WH, Lazar EJ, et al. Internal medicine housestaff and attending physician perceptions of the impact of the New York State Section 405 regulations on working conditions and supervision of residents in two training programs. J Gen Intern Med 1993;8:502-7.

25. Kort KC, Pavone LA, Jensen E, et al. Resident perceptions of the impact of work-hour restrictions on health care delivery and surgical education: time for transformational change. Surgery 2004;136:861-71.

26. Kiernan M, Civetta J, Bartus C, et al. 24 Hours on-call and acute fatigue no longer worsen resident mood under the 80-hour work week regulations. Curr Surg 2006;63:237-41.

27. Cull WL, Mulvey HJ, Jewett EA, et al. Pediatric residency duty hours before and after limitations. Pediatrics 2006;118:e1805-11.

28. Reddy R, Guntupalli K, Alapat P, et al. Sleepiness in medical ICU residents. Chest 2009;135:81-5.

29. Berios I, Surani S, Simmons M. Assessing reaction time among emergency medicine residents working different shift hours. Ann Emerg Med 2009;54:S35.

30. Brown M, Tucker P, Rapport F, et al. The impact of shift patterns on junior doctors' perceptions of fatigue, training, work/life balance and the role of social support. Qual Saf Health Care 2010;19:e36. 
31. Tucker P, Brown M, Dahlgren A, et al. The impact of junior doctors' worktime arrangements on their fatigue and well-being. Scand $J$ Work Environ Health 2010;36:458-65.

32. Arora V, Dunphy C, Chang VY, et al. The effects of on-duty napping on intern sleep time and fatigue. Ann Intern Med 2006;144:792-8.

33. Jackson EJ, Moreton A. Safety during night shifts: a cross-sectional survey of junior doctors' preparation and practice. BMJ Open 2013;3:e003567.

34. Leape LL, Shore MF, Dienstag JL, et al. A culture of disrespect, part 1: the nature and causes of disrespectful behavior by physicians. Acad Med 2012;87:845-52.

35. O'Gallagher MK, Lewis G, Mercieca K, et al. The impact of the European Working Time Regulations on Ophthalmic Specialist Training-a national trainee survey. Int J Surg 2013;19:837-40.

36. Illing JC, Carter M, Thompson NJ, et al. Evidence synthesis on the occurrence, causes, consequences, prevention and management of bullying and harassing behaviours to inform decision making in the NHS. Final report. NIHR Service Delivery and Organisation programme, 2013.

37. Williams ES, Konrad TR, Scheckler WE, et al. Understanding physicians' intentions to withdraw from practice: the role of job satisfaction, job stress, mental and physical health. Health Care Manage Rev 2001;26:7-19.

38. Edwards N, Kornacki MJ, Silversin J. Unhappy doctors: what are the causes and what can be done? BMJ 2002;324:835-8.

39. Visser MRM, Smets EMA, Oort FJ, et al. Stress, satisfaction and burnout among Dutch medical specialists. CMAJ 2003;168:271-5.

40. Morrow G, Burford B, Carter M, et al. The Impact of the Working Time Regulations on medical education and training: Final report on primary research. Report to the GMC, August 2012. http://www. gmc-uk.org/The_Impact_of_the_Working_Time_Regulations_on_ Medical_Education_and_Training__Final_Report_on_Primary Research.pdf_51157039.pdf

41. Ritchie J, Spencer L. Qualitative data analysis for applied policy research. In: Bryman A, Burgess RG. eds. Analysing qualitative data. London: Routledge, 1994:173-94.

42. Temple J. Time for training: a review of the impact of the European Working Time Directive on the quality of training. 2010. http://www. mee.nhs.uk/pdf/JCEWTD_Final\%20report.pdf

43. Auger KA, Sieplinga KR, Simmons JM, et al. Failure to thrive: pediatric residents weigh in on feasibility trial of the proposed 2008 Institute of Medicine work hour restrictions. J Grad Med Educ 2009;1:181-4.

44. Goitein L. Resident workload-let's treat the disease, not just the symptom. JAMA Intern Med 2013;173:655-6.

45. Auger KA, Landrigan CP, Gonzalez del Ray JA, et al. Better rested but more stressed? Evidence of the effects of resident work hour restrictions. Acad Pediatr 2012;12:335-43.

46. Wayne DB, Arora V. Resident duty hours and the delicate balance between education and patient care. J Gen Intern Med 2008;23:1120-1.

47. Ferguson SA, Neall A, Dorrian J. Strategies used by healthcare practitioners to manage fatigue-related risk: beyond work hours. Med Sociol 2013;7:24-33. http://www.medsoconline.org/

48. Buysse DJ, Barzansky B, Dinges D, et al. Sleep, fatigue, and medical training: setting an agenda for optimal learning and patient care. A report from the Conference "Sleep, fatigue and medical training: Optimizing learning and the patient care environment". Sleep 2003;2:218-25.
49. Schein EH. Organisational culture and leadership. 4th edn. Jossey-Bass, 2010.

50. Morrow G, Burford B, Rothwell C, et al. Professionalism in healthcare professionals. Perceptions of professionalism. Final report to the hpc, 2011. http://www.hpc-uk.org/assets/documents/ 10003771Professionalisminhealthcareprofessionals.pdf

51. Rogers AE. The effects of fatigue and sleepiness on nurse performance and patient safety. In: Hughes RG. ed. Patient safety and quality: an evidence-based handbook for nurses. Rockville, MD: Agency for Healthcare Research and Quality (US), 2008:2-509-2-533.

52. Gregory KB, Winn W, Johnson K, et al. Pilot fatigue survey: exploring fatigue factors in air medical operations. Air Med $J$ 2010;29:309-19.

53. Vila B. Impact of long work hours on police officers and the communities they serve. Am J Ind Med 2006;49:972-80.

54. Sabbagh-Ehrlich S, Friedman L, Richter E. Working conditions and fatigue in professional truck drivers at Israeli ports. Inj Prev 2005;11:110-14.

55. Xhelilaj E, Lapa K. The role of human fatigue factor towards maritime casualties. Marit Transport Navigation J 2010;2:23-32.

56. Dong $X$. Long workhours, work scheduling and work-related injuries among construction workers in the United States. Scand J Work Environ Health 2005;31:329-35.

57. Rainbird S, Thompson K, Dawson D. The impact of organisational culture on fatigue management: the case of camaraderie amongst metropolitan train drivers. In: Sargent C, Darwent D, Roach GD. eds. Living in a 24/7 world: the impact of circadian disruption on sleep, work and health. Adelaide: Australasian Chronobiology Society, 2010:29-33.

58. Helmreich RL. On error management: lessons from aviation. BMJ 2000;320:781-5.

59. Sexton JB, Thomas EJ, Helmreich RL. Error, stress and teamwork in medicine and aviation: cross sectional surveys. BMJ 2000;320:745-9.

60. Härmä M. Workhours in relation to work stress, recovery and health. Scand J Work Environ Health 2006;32:502-14.

61. Lindström K. Psychosocial criteria for good work organization. Scand J Work Environ Health 1994;20:123-33.

62. Sparks K, Faragher B, Cooper CL. Well-being and occupational health in the 21st century workplace. J Occup Organ Psychol 2001;74:489-509.

63. Eurofound. Fifth European working conditions survey. Luxembourg: Publications Office of the European Union, 2012. http://www. eurofound.europa.eu/pubdocs/2011/82/en/1/EF1182EN.pdf

64. Van Yperen NW, Hagedoorn M. Do high job demands increase intrinsic motivation or fatigue or both? The role of job control and job social support. Acad Manage J 2003;46:339-48.

65. Costa G, Akerstedt T, Nachreiner F, et al. Flexible working hours, health, and well-being in Europe: some considerations from a SALTSA project. Chronobiol Int 2004;21:831-44.

66. Kandolin I, Huida O. Individual flexibility: an essential pre-requisite in arranging shift schedules for midwives. J Nurs Manag 1996;4:213-17.

67. Francis R. Report of the Mid Staffordshire NHS Foundation Trust public inquiry. Stationery Office, 2013.

68. Davies $\mathrm{H}$, Mannion R. Will prescriptions for cultural change improve the NHS? BMJ 2013;346:f1305.

69. HMSO. Hospital doctors: training for the future. The report of the working group on specialist medical training. HMSO, 1993. 